\title{
CAPITAL SOCIAL NO CONTEXTO DO DESENVOLVIMENTO DA AGRICULTURA FAMILIAR: UM ESTUDO BIBLIOMÉTRICO
}

\author{
SOCIAL CAPITAL IN THE CONTEXT OF FAMILY AGRICULTURE \\ DEVELOPMENT: A BIBLIOMETRIC STUDY
}

\section{CAPITAL SOCIAL EN EL CONTEXTO DEL DESARROLLO AGRÍCOLA FAMILIAR: UN ESTUDIO BIBLIOMÉTRICO}

\author{
Valdir Serafim Junior ${ }^{1}$ \\ https://orcid.org/0000-0002-7494-8131 \\ Adriana Maria de Grandi ${ }^{2}$ \\ https://orcid.org/0000-0002-5917-0536 \\ Fabíola Graciele Besen ${ }^{3}$ \\ https://orcid.org/0000-0002-8740-2920 \\ Sandra Maria Coltre ${ }^{4}$ \\ https://orcid.org/0000-0001-6699-0500 \\ Tércio Vieira de Araújo 5 \\ https://orcid.org/0000-0001-8666-5852
}

Submissão: 12/12/2019 / Aceito: 03/06/2020 / Publicado: 20/01/2021.

Resumo: O objetivo do estudo é identificar as características da produção científica de teses e dissertações sobre Capital Social no contexto da Agricultura Familiar durante o período de 2014 a 2019. A pesquisa caracterizou-se como descritiva e bibliométrica e os dados foram extraídos de dissertações e teses publicados na base de dados da Biblioteca Digital Brasileira de Teses e Dissertações - BDTD. Foram analisadas as regiões mais estudadas, instituições e

\footnotetext{
${ }^{1}$ Bacharel em Ciências Contábeis. Mestre em Extensão Inovadora e Desenvolvimento Rural Sustentável. Atualmente, cursa doutorado em Desenvolvimento Rural Sustentável pela Universidade Estadual do Oeste do Paraná (Unioeste). Professor do Curso de Ciências Contábeis da Unioeste - Campus de Foz do Iguaçu. E-mail: jr_valdir@hotmail.com

${ }^{2}$ Professora associada a no curso de agronomia na Universidade Estadual do Oeste do Paraná - Unioeste Paraná - Brasil Graduação: Engenharia Agrícola - Universidade Estadual do Oeste do Paraná - Unioeste - 1996, Mestrado: Engenharia Agrícola - Universidade Federal de Viçosa - UFV - 1999 Doutorado: Engenharia Agrícola - Universidade Federal de Viçosa - UFV - 2003. E-mail: adrianadegrandi@gmail.com

${ }^{3}$ Bacharel em Ciências Contábeis. Mestre em Extensão Inovadora e Desenvolvimento Rural Sustentável. Atualmente, cursa doutorado em Desenvolvimento Rural Sustentável pela Universidade Estadual do Oeste do Paraná (Unioeste). Professora do Curso de Ciências Contábeis da Unioeste - Campus de Foz do Iguaçu. Email: fabiolagracielebesen@gmail.com

${ }^{4}$ Bacharel em Administração. Mestre em Engenharia da produção. Doutora em Engenharia da Produção pela Universidade Federal de Santa Catarina (UFSC). Professora do Curso de Administração da Universidade Estadual do Oeste do Paraná (Unioeste) - Campus de Foz do Iguaçu. E-mail: sandracutu@gmail.com ${ }^{5}$ Bacharel em Ciências Contábeis. Mestre em Extensão Inovadora e Desenvolvimento Rural Sustentável. Atualmente, cursa doutorado em Desenvolvimento Rural Sustentável pela Universidade Estadual do Oeste do Paraná (Unioeste). Professor do Curso de Ciências Contábeis da Unioeste - Campus de Foz do Iguaçu. Email:professortercio@hotmail.com
} 
programas de pós-graduação, palavras-chave e referencial sobre Capital Social, amostras, objetivos e conclusões. Identificou-se, conforme os resultados que o ano de 2014 teve o maior número de estudos, regionalmente estão concentrados no Nordeste, Centro Oeste e Sudeste brasileiro, destaque para dos estados de Goiás, Ceará e Minas Gerais. As pesquisas sobre o tema capital social e agricultura familiar se mostraram interdisciplinares, foram objeto de estudo em nove áreas de conhecimento, com destaque para as áreas de agronegócio, economia rural e geografia, e quase a totalidade das IES identificadas são públicas e federais, com programas de pós-graduação com notas de avaliação pela Capes conceito 4 e 5.

Palavras - chave: Capital Social, agricultura familiar, bibliometria.

Abstract: The objective of the study is to identify the characteristics of the scientific production of theses and dissertations on Social Capital in the context of Family Agriculture during the period from 2014 to 2019. The research was characterized as descriptive and bibliometric and the data were extracted from published dissertations and theses in the database of the Brazilian Digital Library of Theses and Dissertations - BDTD. The most studied regions, institutions and graduate programs, keywords and reference on Social Capital, samples, objectives and conclusions were analyzed. It was identified, according to the results that the year 2014 had the largest number of studies, are regionally concentrated in the Northeast, Midwest and Southeast Brazil, especially the states of Goiás, Ceará and Minas Gerais. Research on the topic of social capital and family farming has proved to be interdisciplinary, has been the subject of study in nine areas of knowledge, with emphasis on the areas of agribusiness, rural economy and geography, and almost all of the identified HEIs are public and federal, with graduate programs with evaluation grades by Capes concept 4 and 5.

Key words: Social Capital, family farming, bibliometrics.

Resumen: El objetivo del estudio es identificar las características de la producción científica de tesis y disertaciones sobre Capital Social en el contexto de la Agricultura Familiar durante el período de 2014 a 2019. La investigación se caracterizó como descriptiva y bibliométrica y los datos se extrajeron de disertaciones y tesis publicadas. en la base de datos de la Biblioteca Digital Brasileña de Tesis y Disertaciones - BDTD. Se analizaron las regiones, instituciones y programas de posgrado más estudiados, palabras clave y referências sobre Capital Social, muestras, objetivos y conclusiones. Se identificó, según los resultados que el año 2014 tuvo el mayor número de estudios, se concentra regionalmente en el noreste, medio oeste y sudeste de Brasil, especialmente en los estados de Goiás, Ceará y Minas Gerais. La investigación sobre el tema del capital social y la agricultura familiar ha demostrado ser interdisciplinaria, ha sido objeto de estudio en nueve áreas de conocimiento, con énfasis en las áreas de agronegocios, economía rural y geografía, y casi todas las IES identificadas son públicas y federales, con programas de posgrado con calificaciones de evaluación por Capes concepto 4 y 5.

Palabras clave: Capital social, agricultura familiar, bibliometría. 


\section{INTRODUÇÃO}

A literatura brasileira apresenta inúmeras contribuições sejam pelas dissertações e/ou teses dos diferentes Programas de Pós-Graduação Strictu Sensu nacionais que tratam sobre Capital Social. O Desenvolvimento Rural Sustentável - DRS também é um tema de grande relevância, uma vez que procura estabelecer transformações socioeconômicas e ambientais a fim de melhorar as condições de vida no meio rural. Segundo Elesbão (2007) o espaço rural vem sofrendo alterações significativas e além de espaço produtivo, é lugar de vida e interação social. Assim, dada a importância das relações sociais no meio rural, acredita - se que o Capital Social está diretamente relacionado às possibilidades de sua inclusão em processos de desenvolvimento (BARBOSA, 2016).

Historicamente, pode-se verificar a importância acadêmica do tema Capital Social difundida a partir do ano de 1980, destacando-se três autores das ciências sociais: Pierre Bourdieu, com sua obra "Le Capital Social - Notes Provisories" (1980), James Coleman, com a obra "Social Capital in the Creation of human Capital" (1988) e Robert Putnam, em “Making Democracy Work: civic traditions in Moderny Italy”(1993) (BARBOSA, 2014).

Pierre Bourdieu, com a publicação do artigo Le capital social: notes provisoires, publicado em 1980, trouxe a primeira definição [...] Conjunto de recursos atuais ou potenciais que estão ligados à posse de uma rede durável de relações mais ou menos institucionalizadas de interconhecimento e de Inter reconhecimento [...] (BOURDIEU, 1998, p. 67).

Diferente de Bourdieu (1980), que se debruça sobre as redes sociais como a principal forma de Capital Social, Coleman e Putnam, no final dos anos 80 e início dos anos 90, apresentam Capital Social como um diferente grupo de elementos (solidariedade, ação coletiva, canais de informação, normas e sanções sociais, etc..) que moldam as ações dos indivíduos.

Conforme Coleman, Capital Social afirma que "as ações das pessoas são moldadas, redirecionadas, constrangidas pelo contexto social; normas, confiança interpessoal, redes sociais, e a organização social são importantes para o funcionamento não só da sociedade, mas também da economia (COLEMAN, 1988, p. 32). 
Para Putnam (2000) a característica central do capital social é que se trata de um bem público e descreve o capital social como "características da organização social, como confiança, normas e sistemas, que contribuem para aumentar a eficiência da sociedade, facilitando as ações coordenadas" (PUTNAM, 2000, p.117).

Atualmente, a definição de Capital Social possui diferentes enfoques e, dessa forma, aplicações diversas nas pesquisas científicas em diferentes áreas (LUCAS e ZORITA, 2014). No caso do desenvolvimento rural, diversos autores acreditam que para que o desenvolvimento rural aconteça, deve haver a efetiva participação de atores sociais, compreensão das articulações com outros domínios do mundo social, buscando a valorização dos recursos naturais, incremento de renda e inclusão social nas áreas rurais, e isso só se torna possível se houver desenvolvimento do capital social (relações de confiança, reciprocidade) dos agricultores (CAMPANHOLA \& GRAZIANO (2000), FAVARETO (2006), RAMBO et al, (2012).

Bebbington (1999), por exemplo, estudou os capitais no contexto humano como meios de transformação rural a partir da integração social entre os agentes e suas capacidades específicas produtivas, de convívio e de adaptação frente às dificuldades vivenciadas no meio rural (MAZZUCHETTI et al, 2017).

A partir das considerações acima, torna-se importante estudos sobre Capital Social no contexto da Agricultura Familiar, utilizando da pesquisa bibliométrica, trazendo a oportunidade de mapeamento e discussão de produções científicas em seus vários campos de conhecimento, aspectos e dimensões. Desse modo, o presente estudo tem como questão de pesquisa: Qual o perfil da produção científica de teses e dissertações sobre Capital Social no contexto da Agricultura Familiar durante o período de 2014 a 2019 ?

O objetivo do estudo é identificar as características da produção científica de teses e dissertações sobre Capital Social no contexto da Agricultura Familiar durante o período de 2014 a 2019.

Esse estudo se justifica, pois, a junção entre Capital Social e Agricultura Familiar é um tema importante a ser investigado, buscando identificar possíveis efeitos e resultados influenciados pela existência de capital social voltado ao desenvolvimento da Agricultura Familiar, com ênfase nas realidades locais e seus vários atores. Também se justifica pela 
contribuição teórica, uma vez que as pesquisas bibliométricas possibilitam identificar como determinado assunto, no caso da pesquisa, Capital Social e Agricultura Familiar encontramse difundidos no meio científico, identificando pontos fortes e fracos, autores que mais publicaram, os temas mais recorrentes etc.

A presente pesquisa está estruturada em cinco seções, sendo esta, a primeira, em que consta o problema, objetivo, justificativa e estrutura da pesquisa. Em seguida, na segunda seção, são apresentados os conceitos relacionados a Capital Social e Agricultura Familiar; na terceira, é destacada a metodologia utilizada; na quarta, são expostos os resultados do estudo; e por fim, na última seção, apresenta-se as considerações finais, além das referências bibliográficas.

\section{ASPECTOS TEÓRICOS SOBRE AGRICULTURA FAMILIAR E CAPITAL SOCIAL}

Este tópico tem por objetivo apresentar os conceitos relacionados a agricultura familiar e Capital Social, com o intuito de demonstrar a importância do Capital Social para os agricultores familiares (atores sociais) para promover o desenvolvimento rural. Segundo Castro (2006), cada ator tem controle e interesses sobre certos recursos, e assim, o Capital Social constitui um gênero particular de recurso disponível para esse ator.

\section{Agricultura Familiar}

Segundo Schneider (2003), os estudos relacionados a Agricultura Familiar emergiram no Brasil em meados de 1990, sendo que dois eventos impactaram social e politicamente o meio rural. O primeiro foi o crescimento de movimentos sociais, que produziram manifestações políticas que permanecem até a atualidade.

Em segundo, a criação do Pronaf - Programa Nacional de Fortalecimento da Agricultura Familiar no ano de 1996, como resposta as pressões dos movimentos sindicais, promovendo crédito aos pequenos agricultores que estavam afastados de políticas públicas 
desde a década de 1980 e apresentavam dificuldades de manutenção de suas atividades (SCHNEIDER, 2003).

A reorientação dos debates acadêmicos retomados a partir da década de 1990 sobre a ruralidade deu maior visibilidade aos estudos agrários, que até então apontavam baixo interesse de pesquisadores, ampliando o escopo temático para além da reforma agrária e assentamentos, migrações e impactos dos progresso tecnológico, afirmando-se a temática ambiental e da sustentabilidade, como a Agricultura Familiar, a configuração dos mercados de trabalho e a dinâmica ocupacional da população rural (SCHNEIDER, 2003).

Abramovay (1997) define agricultura familiar, destacando alguns aspectos relevantes:

\begin{abstract}
A agricultura familiar é aquela em que a gestão, a propriedade e a maior parte do trabalho vêm de indivíduos que mantêm entre si laços de sangue ou de parentesco. Que esta definição não seja unânime e muitas vezes tampouco operacional é perfeitamente compreensível, já que os diferentes setores sociais e suas representações constroem categorias científicas que servirão a certas finalidades práticas: a definição de agricultura familiar, para fins de crédito, pode não ser exatamente a mesma daquela estabelecida com finalidades de quantificação estatística num estudo acadêmico. $\mathrm{O}$ importante é que estes três atributos básicos (gestão, propriedade e trabalho familiares) estão presentes em todas elas (ABRAMOVAY, 1997, p. 03).
\end{abstract}

A organização da Agricultura Familiar está pautada em modos de exploração, tamanho e gestão da propriedade, baseado na terra, trabalho e família, o que a diferencia da agricultura patronal, que tem como característica um maior nível de tecnificação, investimento e níveis de produção em escala. Para Wanderley (2000) o mundo rural brasileiro transformou-se, reconhecendo a Agricultura Familiar oficialmente como um ator social, onde outrora eram considerados os pobres do campo, pequenos produtores ou de baixa renda.

A partir desse novo cenário, de acordo com Long e Van Der Ploeg (2011), os agricultores passaram a ser vistos como atores sociais. "Eles se tornam participantes ativos que processam informações e utilizam estratégias nas suas relações com vários atores locais, assim como com instituições e pessoas externas" (LONG e VAN DER PLOEG, 2011, p.24).

Assim, é importante analisar dentro do contexto da agricultura familiar o capital social, pois o mesmo, segundo Bourdieu (1980) está sempre relacionado a um grupo (rede social). Segundo Putnam (2000), para uma boa governança, estabilidade política e mesmo para o desenvolvimento econômico, o Capital Social pode tornar-se mais importante do que 
o capital físico e humano, porém, criar Capital Social não é fácil, mas é essencial para o funcionamento da democracia.

\section{Capital Social}

Historicamente, pode-se verificar a importância acadêmica do tema Capital Social difundida a partir do ano de 1980, destacando-se três autores das ciências sociais: Pierre Bourdieu, com sua obra "Le Capital Social - Notes Provisories" (1980), James Coleman, com a obra "Social Capital in the Creation of human Capital" (1988) e Robert Putnam, em “Making Democracy Work: civic traditions in Moderny Italy”(1993) (BARBOSA, 2014).

Pela definição de Bourdieu (1980), referindo-se as vantagens e oportunidade de se pertencer a certas comunidades, Capital Social é o aglomerado de recursos, reais ou mesmo potenciais, porém vinculados a uma rede durável de relações oficializadas de recíproco conhecimento ou reconhecimento. Para Bourdieu se alavanca o Capital Social a partir dos pensamentos e atitudes do grupo da comunidade, sendo que a partir de seu aumento, se interfere nos níveis do grau de pertencimento do cidadão com a comunidade.

Os estudos de Coleman derivam do interesse na associação de abordagens econômicas e sociológicas, concentrando inicialmente estudos baseados na experiência de escolas públicas e católicas, comparando seus desempenhos e analisando o Capital Social como um modo de compreensão da relação entre o alcance educacional e desigualdade social, assim o definindo como a quantidade de elementos próprios nas relações familiares e na organização social, uteis para o processo de desenvolvimento cognitivo ou social (ALBAGLI e MACIEL, 2002).

Coleman (1988) define Capital Social como:

Social capital is defined by its function. It is not a single entity but a variety of diferente entities, with two elements in common: they all consisst of some aspect oF social structures, and they facilitate certain actions of actors - wheter persons or corporate actors - within the structure (COLEMAN, 1988: S98)

Diferente de Coleman, que entende o capital Social enquanto conjunto de recursos que possibilita aos indivíduos a satisfação de seus objetivos, Ostrom, Sabourin e Fukuyama (2001), “concebem o capital social como o elo estabelecido entre sujeitos com origem em 
motivos pessoais, cujo efeito é a produção de normas comuns" (SANTOS, VIEIRA E SANTOS, 2019, p.80).

Albagli e Maciel (2002) relatam que a popularização do conceito de Capital Social e sua incorporação no discurso político pode ser atribuído a Robert Putnam. A característica central do Capital Social é que se trata de um bem público e Putnam (2000), assim define o Capital Social como "características da organização social, como confiança, normas e sistemas, que contribuem para aumentar a eficiência da sociedade, facilitando as ações coordenadas" (PUTNAM, 2000, p.117).

Para Milani (2007), simbolicamente pode-se relacionar o Capital Social com o capital econômico, pois ambos trazem benefícios, porém o Capital Social tem como característica principal o não esgotamento com o uso, mas, pode se esgotar pela falta de uso. O Capital Social é propriedade de indivíduos ou de grupos, proporcionando inicialmente que as pessoas ou grupos mais favorecidos êxito na competição social, este atributo permite o aumento da capacidade de solução de problemas de ação coletiva.

O Quadro 01 apresenta de forma resumida alguns enfoques dos conceitos de Capital Social:

Quadro 01 - Enfoques dos conceitos de capital social Referência/Período Enfoque do Capital Social

\begin{tabular}{|l|l|}
\hline Referência/Período & Enfoque do Capital Social \\
\hline Lyda Judson Hanifan (década de 1910) & $\begin{array}{l}\text { Rede de relações sociais, culturais ou econômicas entre } \\
\text { pessoas e comunidade em centros comunitários de escolas } \\
\text { rurais. }\end{array}$ \\
\hline John Seeley (década de 1950) & $\begin{array}{l}\text { Pertencimento de moradores suburbanos a associações } \\
\text { como forma de acesso a bens e direitos. }\end{array}$ \\
\hline Jane Jacobs (década de 1960) & $\begin{array}{l}\text { Redes informais de sociabilidade nas grandes metrópoles } \\
\text { ligadas à segurança pública }\end{array}$ \\
\hline Glenn Loury e Ivan Light (década de 1970) & $\begin{array}{l}\text { Desenvolvimento econômico ausente em grandes cidades e } \\
\text { ausência de confiança e cooperação entre a comunidade } \\
\text { afroamericana. }\end{array}$ \\
\hline $\begin{array}{l}\text { Pierre Bordieu e Ekkehart Schlicht (década } \\
\text { de 1980) }\end{array}$ & $\begin{array}{l}\text { Agregador de recursos ligado ao pertencimento. } \\
\text { Importância da organização social e ordem moral para a } \\
\text { economia }\end{array}$ \\
\hline James Coleman (final da década de 1980) & Mecanismo de satisfação e criação de bens. \\
\hline Robert Putnam (década de 1990) & Papel na sociedade civil norte-americana e italiana. \\
\hline Francis Fukuyama (década de 1990) & Prosperidade econômica e cultural. \\
\hline
\end{tabular}
Fonte: MAZZUCHETTI, STOFELL, TARIFA (2017) adaptado de Genari (2010).

Abramovay (2000), sobre Capital Social, afirma que as ações dos indivíduos não são independentes, na formulação de objetivos não agem de forma isolada e não 
necessariamente apresentam comportamento estritamente egoísta; assim as estruturas sociais apresentam-se como recursos disponíveis, proporcionando aos atores o alcance de objetivos não atingidos na sua ausência.

No cenário rural, Bebbington (1999), estudou os capitais no contexto humano como meios de transformação rural a partir da integração social entre os agentes e suas capacidades específicas produtivas, de convívio e de adaptação frente às dificuldades vivenciadas no meio rural (MAZZUCHETTI et al, 2017).

A partir da perspectiva dos agricultores com poder de organização e ação, Lucas e Zorita (2014, p.38) apresentam Capital Social como [...] a capacidade de organização dos atores sociais, ou seja, capacidade de trabalhar em conjunto com o objetivo de alcançar o bem-estar coletivo em um determinado espaço e momento [...]

Quando o rural é considerado somente como base física de produção agrícola, o esvaziamento político, social, econômico e cultural continuará ocorrendo, porém se revelado potenciais baseados em um conjunto de atividades e mercados, os seus limites poderão ser ampliados. Assim, o fortalecimento do Capital Social é primordial para a construção de novas instituições propícias ao desenvolvimento rural (ABRAMOVAY, 2000).

\section{PROCEDIMENTOS METODOLÓGICOS}

O presente estudo tem como objetivo analisar a produção científica relacionada ao tema Capital Social no contexto da Agricultura Familiar no período de 2014 a 2019, classificando-se o estudo quanto a sua tipologia como descritivo e bibliográfico. Conforme Cervo e Bervian (1983), a pesquisa bibliográfica busca explicar um problema a partir de referenciais teóricos publicados em documentos. É descritivo, pois apresenta os resultados encontrados após o levantamento bibliométrico de dissertações de mestrado e teses de doutorados na base de dados da Biblioteca Digital Brasileira de Teses e Dissertações BDTD.

Em relação aos procedimentos, caracteriza-se como bibliométrica. A pesquisa bibliométrica, segundo Araújo (2006), permite a identificação e descrição de padrões e tendências na produção do conhecimento científico. A bibliometria foi desenvolvida pela 
Biblioteconomia e pelas Ciências da Informação e compreende um conjunto de métodos de pesquisa que está em constante evolução, utiliza-se de análises quantitativa, estatística e de visualização de dados, não somente destinada ao mapeamento da estrutura do conhecimento de um campo científico, mas também como ferramenta primária para a análise das decisões na construção conhecimento por parte dos pesquisadores (Vanti, 2002).

A abordagem do estudo se qualifica como quantitativa, pois se utilizou de dados numéricos para identificação e comparação de informações comuns entre os estudos selecionados, como também análise de conteúdo quanto seus objetivos, amostras e conclusões.

A Tabela 1 descreve as etapas efetuadas na coleta de dados, como parâmetro no processo de busca na base de dados da BDTD. No primeiro momento buscou-se as dissertações e teses que utilizavam em seu título e/ou palavra-chave a expressão "Capital Social", com retorno de 914 estudos, sendo 632 dissertações e 282 teses. Na sequência, refinou-se a busca considerando a inclusão da expressão "Agricultura", e com as duas expressões foram selecionados 686 estudos, sendo 478 dissertações e 208 teses. Em seguida, a busca utilizou a expressão "Capital Social” em conjunto com "Agricultura Familiar", resultando em 48 dissertações e 15 teses.

Por último, fez-se o corte temporal de 2014 a 2019, buscando uma amostra atualizada do tema, totalizando 26 dissertações e 8 teses, excluindo-se duplicidades e temáticas que não contribuiriam para análise, ou seja, desviada do eixo proposto que é Capital Social, resultando em 13 objetos para a base de pesquisa, representados por 8 dissertações e 5 teses.

Tabela 1 - Histórico de busca e seleção de dissertações e teses para análise de dados

\begin{tabular}{|l|l|c|c|c|}
\hline Histórico & Expressões no título e/ou palavras chave & Dissertações & Teses & Total \\
\hline $1^{\circ}$ Busca & "Capital Social" & 632 & 282 & 914 \\
\hline $2^{\circ}$ Busca & "Capital Social" e "Agricultura" & 478 & 208 & 686 \\
\hline $3^{\circ}$ Busca & "Capital Social" e "Agricultura Familiar" & 48 & 15 & 63 \\
\hline $4^{\circ}$ Busca & Filtro: "Ano de defesa": 2014 a 2019 & 26 & 8 & 34 \\
\hline $\begin{array}{l}\text { Após ajustes por duplicidade, idioma e temática fora do } \\
\text { eixo de Capital Social }\end{array}$ & $\mathbf{8}$ & $\mathbf{5}$ & $\mathbf{1 3}$ \\
\hline
\end{tabular}

Fonte: Elaborado pelos autores, adaptado de BDTD, 2019.

O Quadro 2 relaciona as dissertações e teses selecionadas, utilizando-se para as análises das publicações catalogadas abordagens de pesquisa qualitativa e quantitativa. 
Quadro 2 - Relação de dissertações e teses objetos da pesquisa

\begin{tabular}{|c|c|c|c|c|c|}
\hline $\mathbf{N}^{\mathbf{0}}$ & Título & Tipo & Defesa & Autor(a) & Universidade \\
\hline 1 & $\begin{array}{l}\text { Capital Social e as associações de Agricultura } \\
\text { Familiar em Paudalho, Pernambuco }\end{array}$ & Dissertação & 2014 & $\begin{array}{l}\text { Sylvia Karla } \\
\text { Gomes Barbosa }\end{array}$ & $\begin{array}{l}\text { Universidade Federal } \\
\text { Rural de Pernambuco }\end{array}$ \\
\hline 2 & $\begin{array}{l}\text { Capital Social e redes: uma análise do programa de } \\
\text { aquisição de alimentos da Agricultura Familiar }\end{array}$ & Tese & 2014 & $\begin{array}{l}\text { Leandro de Lima } \\
\text { Santos }\end{array}$ & $\begin{array}{l}\text { Universidade Federal de } \\
\text { Goiás }\end{array}$ \\
\hline 3 & $\begin{array}{l}\text { O efeito do programa territorial nas relações sociais } \\
\text { dos agricultores familiares do território da cidadania } \\
\text { do vale do Rio Vermelho - Go }\end{array}$ & Dissertação & 2014 & $\begin{array}{l}\text { Ricardo de } \\
\text { Siqueira Camargo }\end{array}$ & $\begin{array}{l}\text { Universidade Federal de } \\
\text { Goiás }\end{array}$ \\
\hline 4 & $\begin{array}{l}\text { Desenvolvimento rural sustentável e as condições de } \\
\text { vida dos agricultores familiares na Zona da Mata } \\
\text { mineira: os casos comparados de Tombos e } \\
\text { Araponga }\end{array}$ & Tese & 2014 & $\begin{array}{l}\text { Brasilina Elisete } \\
\text { Reis de Oliveira }\end{array}$ & $\begin{array}{l}\text { Universidade Federal de } \\
\text { Goiás }\end{array}$ \\
\hline 5 & $\begin{array}{l}\text { Avaliação dos impactos do programa de aquisição de } \\
\text { alimentos (PAA) no estado do Ceará: O caso do mel }\end{array}$ & Dissertação & 2014 & \begin{tabular}{ll|} 
Diogo & Brito \\
Sobreira & \\
\end{tabular} & $\begin{array}{l}\text { Universidade Federal do } \\
\text { Ceará }\end{array}$ \\
\hline 6 & $\begin{array}{l}\text { Capital Social e desenvolvimento da Agricultura } \\
\text { Familiar no Ceará }\end{array}$ & Dissertação & 2015 & $\begin{array}{l}\text { Gerlânia Maria } \\
\text { Rocha Souza }\end{array}$ & $\begin{array}{l}\text { Universidade Federal do } \\
\text { Ceará }\end{array}$ \\
\hline 7 & $\begin{array}{l}\text { Capital cultural e território: os nós, os laços e a trama } \\
\text { das redes de agricultores familiares do município de } \\
\text { Nossa Senhora da Glória - SE }\end{array}$ & Tese & 2015 & $\begin{array}{l}\text { José Franco de } \\
\text { Azevedo }\end{array}$ & $\begin{array}{l}\text { Universidade Federal de } \\
\text { Sergipe }\end{array}$ \\
\hline 8 & $\begin{array}{l}\text { Agricultura Familiar e Mercados Institucionais } \\
\text { (protegidos): estudo sobre o Programa de Aquisição } \\
\text { de Alimentos (CPR Doação) em Boa Vista, Roraima. }\end{array}$ & Tese & 2015 & $\begin{array}{l}\text { João Henrique } \\
\text { Rocha }\end{array}$ & $\begin{array}{l}\text { Universidade Federal de } \\
\text { Pelotas }\end{array}$ \\
\hline 9 & $\begin{array}{l}\text { Redes sociais e acesso a políticas públicas de compra } \\
\text { governamental da Agricultura Familiar: um estudo } \\
\text { de caso do município de Guaraciaba- MG }\end{array}$ & Dissertação & 2016 & $\begin{array}{l}\text { José } \quad \text { Antônio } \\
\text { Machado }\end{array}$ & $\begin{array}{l}\text { Universidade Federal de } \\
\text { Viçosa }\end{array}$ \\
\hline 10 & $\begin{array}{l}\text { Alcance de políticas públicas federais no } \\
\text { cooperativismo da Agricultura Familiar em Goiás do } \\
\text { ano de } 2007 \text { ao ano de } 2014\end{array}$ & Dissertação & 2016 & $\begin{array}{l}\text { Rodrigo Gonçalves } \\
\text { de Souza }\end{array}$ & $\begin{array}{l}\text { Universidade Federal de } \\
\text { Goiás }\end{array}$ \\
\hline 11 & $\begin{array}{l}\text { Capital Social, pluriatividade e desenvolvimento } \\
\text { local: tratos e retratos no sudoeste da Bahia }\end{array}$ & Tese & 2016 & $\begin{array}{l}\text { Gabriela Silveira } \\
\text { Rocha }\end{array}$ & $\begin{array}{l}\text { Universidade Federal de } \\
\text { Sergipe }\end{array}$ \\
\hline 12 & $\begin{array}{l}\text { Redes sociais de trabalho do agricultor familiar de } \\
\text { Maranguape, Ceará }\end{array}$ & Dissertação & 2017 & $\begin{array}{l}\text { José Wilton Lima } \\
\text { Martins }\end{array}$ & $\begin{array}{l}\text { Universidade } \\
\text { Fortaleza }\end{array}$ \\
\hline 13 & $\begin{array}{l}\text { Pronaf, empreendedorismo rural e Capital Social: } \\
\text { uma análise das famílias assentadas no município de } \\
\text { Rio Verde - GO }\end{array}$ & Dissertação & 2019 & $\begin{array}{l}\text { Leonardo } \\
\text { Guimarães } \\
\text { Medeiros }\end{array}$ & $\begin{array}{l}\text { Universidade Federal de } \\
\text { Goiás }\end{array}$ \\
\hline
\end{tabular}

Fonte: Elaborado pelos autores, adaptado de BDTD, 2019.

De posse da base de dissertações e teses, foi utilizado o software Excel para a organização e evidenciação das principais características consideradas no estudo. Essas características estão relacionadas ao ano da defesa, o Estado onde a pesquisa foi realizada, a quantidade de obras e principais autores utilizados como referência ao tema de Capital Social, as IES - Instituições de Ensino Superior e seus respectivos programas de pós-graduação, o ano de fundação dos programas e suas áreas básicas, conceito capes, as amostras utilizadas nos estudos e por fim seus objetivos e resultados. 


\section{ANÁLISE DOS DADOS}

\section{Análise das questões temporais e territoriais relacionadas ao portfólio de dissertações de mestrado e teses de doutorado da pesquisa}

Como análise preliminar de resultados, são apresentados abaixo na Tabela 2 questões temporais e territoriais relacionadas ao portfólio de dissertações de mestrado e teses de doutorado objetos do estudo. Identificou-se que na coleta efetuada, o tema Capital Social está relacionado na maioria dos casos, com dissertações de mestrado e na análise de séries temporais uma maior concentração de defesas no ano de 2014, seguido pelos anos de 2015 e 2016.

Quanto as regiões estudadas, apresentaram-se em grande maioria relacionadas à região Nordeste seguida pela região Centro Oeste e Sudeste, aparecendo em destaque os estados de Goiás, Ceará e Minas Gerais.

Tabela 2 - Caracterização temporal e territorial das pesquisas objeto do estudo

\begin{tabular}{|c|c|c|c|c|c|}
\hline Tipo & Qtde & $\%$ & Estado & Qtde & $\%$ \\
\hline Dissertação & 8 & $61,5 \%$ & Goiás - Centro Oeste & 4 & $30,8 \%$ \\
\hline Tese & 5 & $38,5 \%$ & Ceará - Nordeste & 3 & $23,1 \%$ \\
\hline TOTAL & 13 & $100 \%$ & Minas Gerais - Sudeste & 2 & $15,4 \%$ \\
\hline Ano & Qtde & $\%$ & Bahia - Nordeste & 1 & $7,7 \%$ \\
\hline Defesa no ano de 2014 & 5 & $38,5 \%$ & Pernambuco - Nordeste & 1 & $7,7 \%$ \\
\hline Defesa no ano de 2015 & 3 & $23,1 \%$ & Roraima - Norte & 1 & $7,7 \%$ \\
\hline Defesa no ano de 2016 & 3 & $23,1 \%$ & Sergipe - Nordeste & 1 & $7,7 \%$ \\
\hline Defesa no ano de 2017 & 1 & $7,7 \%$ & TOTAL & 13 & $100 \%$ \\
\hline Defesa no ano de 2019 & 1 & $7,7 \%$ & \multicolumn{3}{|c|}{ Norte $=1(7,69 \%) /$ Nordeste $=6(46,15 \%)$} \\
\hline TOTAL & 13 & $100 \%$ & \multicolumn{3}{|c|}{ Centro Oeste $=4(30,77 \%) /$ Sudeste $=2(15,38 \%)$} \\
\hline
\end{tabular}

Fonte: Dados da pesquisa, 2019.

As IES - Instituições de Ensino Superior, na configuração de agente social por natureza, conduzem e potencializam processos de desenvolvimento local e regional, na Tabela 3 é apresentado o quantitativo das pesquisas por IES e por seus respectivos PPG Programas de Pós-Graduação. 
Primeiramente, ressalta-se a quase totalidade de instituições públicas federais, como exclusão somente da UNIFOR - Universidade de Fortaleza. Como entidade privada filantrópica, liderando em quantitativo de pesquisas a UFG - Universidade Federal de Goiás que representa 38,5\% da amostra, seguida pela UFC - Universidade Federal do Ceará e UFS - Universidade Federal de Sergipe, ambas com 15,4\%. As demais representaram somente uma pesquisa relacionada ao tema, sendo tese ou dissertação.

Dentro dos programas de pós-graduação, verificou-se que o tema Capital Social é objeto de estudo de diversas áreas. Identificou-se 9 áreas do conhecimento, com destaque para os programas de voltados ao Agronegócio, Economia Rural e Geografia que apresentaram maiores índices, mas não menos importantes. Houve estudos sobre o tema relacionado às áreas de Administração e Desenvolvimento Rural, Ciências Ambientais, Extensão Rural, Psicologia, Sistemas de Produção Agrícola Familiar e Sociologia.

Na pesquisa de Flores e Marini (2018), que analisaram capital social e governança local na temática dos arranjos produtivos locais, por meio de pesquisa bibliométrica em fontes secundárias disponíveis de forma online na Biblioteca Digital de Teses e Dissertações no Brasil, identificaram que quanto aos programas Strictu Sensu de Mestrado e Doutorado aos quais pertencem as obras no presente trabalho, são os seguintes cursos de: Administração, Administração de Empresas, Economia, Extensão Rural e Geografia, corroborando com os achados dessa pesquisa.

Tabela 3 - IES - Instituições de Ensino Superior e PPG - Programas de PósGraduação e Conceito Capes

\begin{tabular}{|l|c|c|c|c|}
\hline IES / PPG & & Dissertação & Tese & TOTAL \\
\hline \multirow{2}{*}{ UFG - Universidade Federal de Goiás } & Contagem & 3 & 2 & $\mathbf{5}$ \\
\cline { 2 - 5 } & $\%$ do Total & $23,1 \%$ & $15,4 \%$ & $\mathbf{3 8 , 5} \%$ \\
\hline \multirow{2}{*}{ UFC - Universidade Federal do Ceará } & Contagem & 2 & 0 & $\mathbf{2}$ \\
\cline { 2 - 5 } & $\%$ do Total & $15,4 \%$ & $0,0 \%$ & $\mathbf{1 5 , 4 \%}$ \\
\hline \multirow{2}{*}{ UFS - Universidade Federal de Sergipe } & Contagem & 0 & 2 & $\mathbf{2}$ \\
\cline { 2 - 5 } & $\%$ do Total & $0,0 \%$ & $15,4 \%$ & $\mathbf{1 5 , 4 \%}$ \\
\hline \multirow{2}{*}{ UFPEL - Universidade Federal de Pelotas } & Contagem & 0 & 1 & $\mathbf{1}$ \\
\cline { 2 - 5 } & $\%$ do Total & $0,0 \%$ & $7,7 \%$ & $\mathbf{7 , 7 \%}$ \\
\hline \multirow{2}{*}{ UFRPE - Universidade Federal Rural de Pernambuco } & Contagem & 1 & 0 & $\mathbf{1}$ \\
\cline { 2 - 5 } & \% do Total & $7,7 \%$ & $0,0 \%$ & $\mathbf{7 , 7 \%}$ \\
\hline \multirow{2}{*}{ UFV - Universidade Federal de Viçosa } & Contagem & 1 & 0 & $\mathbf{1}$ \\
\cline { 2 - 5 } & $\%$ do Total & $7,7 \%$ & $0,0 \%$ & $\mathbf{7 , 7 \%}$ \\
\hline \multirow{2}{*}{ UNIFOR - Universidade de Fortaleza } & Contagem & 1 & 0 & $\mathbf{1}$ \\
\cline { 2 - 5 } & $\%$ do Total & $7,7 \%$ & $0,0 \%$ & $\mathbf{7 , 7 \%}$ \\
\hline \multirow{2}{*}{ TOTAL } & Contagem & $\mathbf{8}$ & $\mathbf{5}$ & $\mathbf{1 3}$ \\
\cline { 2 - 5 } & \% do Total & $\mathbf{6 1 , 5 \%}$ & $\mathbf{3 8 , 5 \%}$ & $\mathbf{1 0 0 , 0 \%}$ \\
\hline
\end{tabular}

DOI: http://dx.doi.org/10.22295/grifos.v30i52.5254 | Edição Vol. 30, Núm. 52, 2021. 


\begin{tabular}{|c|c|c|c|c|}
\hline \multirow{2}{*}{ PPG em Agronegócio - UFG - Capes 4} & Contagem & 3 & 0 & 3 \\
\hline & $\%$ do Total & $23,1 \%$ & $0,0 \%$ & $23,1 \%$ \\
\hline \multirow{2}{*}{ PPG em Economia Rural - UFC - Capes 4} & Contagem & 2 & 0 & 2 \\
\hline & $\%$ do Total & $15,4 \%$ & $0,0 \%$ & $15,4 \%$ \\
\hline \multirow{2}{*}{ PPG em Geografia - UFS - Capes 4} & Contagem & 0 & 2 & 2 \\
\hline & $\%$ do Total & $0,0 \%$ & $15,4 \%$ & $15,4 \%$ \\
\hline \multirow{2}{*}{$\begin{array}{l}\text { PPG em Adm. e Desenvolvimento Rural - UFRPE - } \\
\text { Capes } 3\end{array}$} & Contagem & 1 & 0 & 1 \\
\hline & $\%$ do Total & $7,7 \%$ & $0,0 \%$ & $7,7 \%$ \\
\hline \multirow{2}{*}{ PPG em Ciências Ambientais - UFG - Capes 6} & Contagem & 0 & 1 & 1 \\
\hline & $\%$ do Total & $0,0 \%$ & $7,7 \%$ & $7,7 \%$ \\
\hline \multirow{2}{*}{ PPG em Extensão Rural - UFV - Capes 4} & Contagem & 1 & 0 & 1 \\
\hline & $\%$ do Total & $7,7 \%$ & $0,0 \%$ & $7,7 \%$ \\
\hline \multirow{2}{*}{ PPG em Psicologia - UNIFOR - Capes 4} & Contagem & 1 & 0 & 1 \\
\hline & $\%$ do Total & $7,7 \%$ & $0,0 \%$ & $7,7 \%$ \\
\hline \multirow{2}{*}{$\begin{array}{l}\text { PPG em Sistemas de Produção Agrícola Familiar - } \\
\text { UFPEL - Capes } 5\end{array}$} & Contagem & 0 & 1 & 1 \\
\hline & $\%$ do Total & $0,0 \%$ & $7,7 \%$ & $7,7 \%$ \\
\hline \multirow{2}{*}{ PPG em Sociologia - UFG - Capes 2} & Contagem & 0 & 1 & 1 \\
\hline & $\%$ do Total & $0,0 \%$ & $7,7 \%$ & $7,7 \%$ \\
\hline \multirow{2}{*}{ TOTAL } & Contagem & 8 & 5 & 13 \\
\hline & \% do Total & $61,5 \%$ & $38,5 \%$ & $100,0 \%$ \\
\hline
\end{tabular}

Fonte: Dados da pesquisa, 2019.

Quanto a avaliação periódica da Capes, a grande maioria dos programas apresenta um bom e ótimo desempenho, representados pelas avaliações 4 e 5 e um programa indica desempenho de alto padrão e nível internacional, avaliado com nota 6 . 0 desempenho regular representado pela nota 3 e insatisfatório pela nota 2 foram relacionados a dois programas de pós graduação, o que pode no caso da menor avaliação comprometer a autorização de funcionamento do programa.

$\mathrm{Na}$ tentativa de analisar o nível de profundidade do referencial destinado ao tema Capital Social, buscou-se levantar o número de obras utilizadas pelos autores dentro de suas teses e dissertações. A Tabela 4 indica que foram utilizadas de 6 a 10 obras em cada referencial, principalmente nas dissertações de mestrado, seguida pela utilização de 11 a 15 obras, indicando que existem diversos autores que retratam o tema e em diversas abordagens.

Tabela 4 - Quantidade de obras referenciadas sobre Capital Social e páginas das dissertações e teses

\begin{tabular}{|l|c|c|c|c|}
\hline Obras sobre Capital Social / N de páginas & & Dissertação & Tese & TOTAL \\
\hline \multirow{2}{*}{ Até 5 obras referenciadas } & Contagem & 0 & 1 & $\mathbf{1}$ \\
\cline { 2 - 5 } & $\%$ do Total & $0,0 \%$ & $7,7 \%$ & $\mathbf{7 , 7 \%}$ \\
\hline \multirow{2}{*}{ Acima de 5 até 10 obras referenciadas } & Contagem & 5 & 1 & $\mathbf{6}$ \\
\cline { 2 - 5 } & $\%$ do Total & $38,5 \%$ & $7,7 \%$ & $\mathbf{4 6 , 2 \%}$ \\
\hline \multirow{2}{*}{ Acima de 10 até 15 obras referenciadas } & Contagem & 2 & 1 & $\mathbf{3}$ \\
\cline { 2 - 5 } & $\%$ do Total & $15,4 \%$ & $7,7 \%$ & $\mathbf{2 3 , 1 \%}$ \\
\hline \multirow{2}{*}{ Acima de 15 até 20 obras referenciadas } & Contagem & 0 & 1 & $\mathbf{1}$ \\
\cline { 2 - 5 } & $\%$ do Total & $0,0 \%$ & $7,7 \%$ & $\mathbf{7 , 7 \%}$ \\
\hline
\end{tabular}

DOI: http://dx.doi.org/10.22295/grifos.v30i52.5254 | Edição Vol. 30, Núm. 52, 2021. 


\begin{tabular}{|l|c|c|c|c|}
\hline \multirow{2}{*}{ Acima de 25 até 30 obras referenciadas } & Contagem & 0 & 1 & $\mathbf{1}$ \\
\cline { 2 - 5 } Acima de 30 obras referenciadas & do Total & $0,0 \%$ & $7,7 \%$ & $\mathbf{7 , 7 \%}$ \\
\hline \multirow{2}{*}{ TOTAL } & Contagem & 1 & 0 & $\mathbf{1}$ \\
\cline { 2 - 5 } & Contagem & $7,7 \%$ & $0,0 \%$ & $\mathbf{7 , 7 \%}$ \\
\cline { 2 - 5 } Até 100 páginas & Contagem & $\mathbf{8}$ & $\mathbf{5}$ & $\mathbf{1 3}$ \\
\hline \multirow{2}{*}{ Acima de 100 até 150 páginas } & $\%$ do Total & $23,1 \%$ & $0,0 \%$ & $\mathbf{2 3 , 1 \%}$ \\
\hline \multirow{2}{*}{ Acima de 150 até 200 páginas } & Contagem & 3 & 0 & $\mathbf{3}$ \\
\cline { 2 - 5 } & \% do Total & $23,1 \%$ & $0,0 \%$ & $\mathbf{2 3 , 1 \%}$ \\
\hline \multirow{2}{*}{ Acima de 200 páginas } & Contagem & 2 & 2 & $\mathbf{4}$ \\
\cline { 2 - 5 } & $\%$ do Total & $15,4 \%$ & $15,4 \%$ & $\mathbf{3 0 , 8} \%$ \\
\hline \multirow{2}{*}{ TOTAL } & Contagem & 0 & 3 & $\mathbf{3}$ \\
\cline { 2 - 5 } & $\%$ do Total & $0,0 \%$ & $23,1 \%$ & $\mathbf{2 3 , 1 \%}$ \\
\cline { 2 - 5 } & Contagem & $\mathbf{8}$ & $\mathbf{5}$ & $\mathbf{1 3}$ \\
\cline { 2 - 5 } & \% do Total & $\mathbf{6 1 , 5 \%}$ & $\mathbf{3 8 , 5 \%}$ & $\mathbf{1 0 0 , 0 \%}$ \\
\hline
\end{tabular}

Fonte: Dados da pesquisa, 2019.

Quanto ao tamanho das pesquisas, identificou-se uma concordância com o tipo da pós-graduação, no caso dos mestrados que são cursos analíticos e menor duração, em média de dois anos, as dissertações concentraram-se em até 150 páginas, com menor frequência as que representam quantitativo de páginas superior a 150 e até 200.

Em relação aos programas em nível de doutorado, os mesmos possuem um maior nível de profundidade em relação à área de pesquisa e maior tempo de duração, em média quatro anos, tendo com contribuição final uma nova visão sobre o tema, demonstrando uma maior complexibilidade e consequentemente um maior aprofundamento no tema, encontrando uma maior quantidade de páginas nas teses, iniciando já acima de 150 e com maior concentração superior a 200 páginas.

\section{Análise dos objetivos, autores e temas mais estudados relacionados ao portfólio de dissertações de mestrado e teses de doutorado da pesquisa}

Na Figura 1, utilizou-se a nuvem de palavras chaves como ferramenta de análise, identificando através desta, as palavras chaves preponderantes e os conceitos e ideias indexadas nas pesquisas. De forma mais evidente, encontram-se as palavras "CAPITAL" e "SOCIAL" representando o foco principal dos estudos, seguido pela representação dos atores a serem estudados relativo as palavras "AGRICULTURA" e "FAMILIAR". Em seguida, as palavras "DESENVOLVIMENTO" e "RURAL", apontando não a resposta do problema de pesquisa, mas representando um núcleo de sentido que deixa claro que os estudos têm como 
eixo a importância do Capital Social para o desenvolvimento da Agricultura Familiar e o meio rural.

Figura 1 - Nuvem de palavras chave

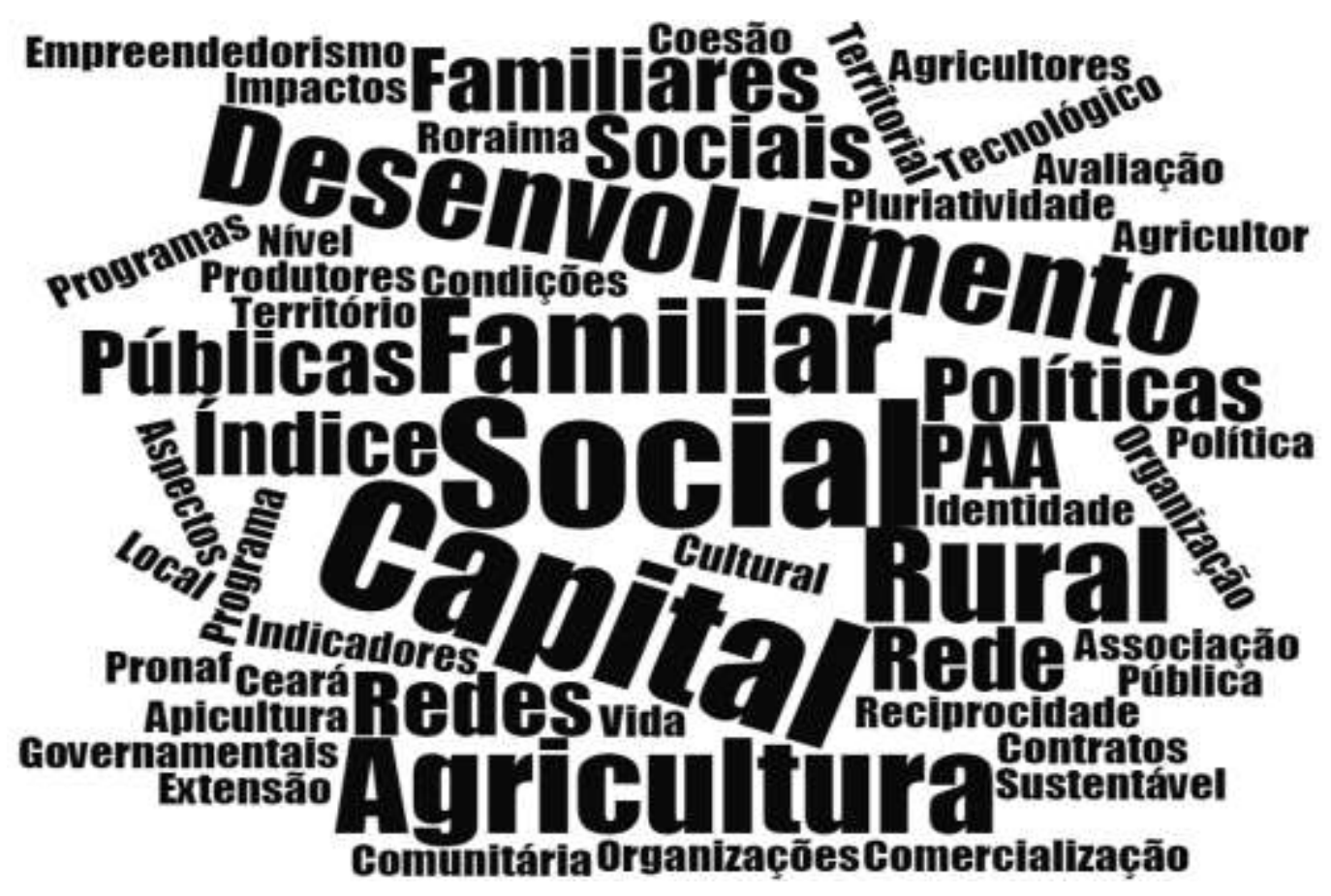

Fonte: Dados da pesquisa, 2019.

As demais palavras identificadas na nuvem estão amplamente relacionadas a diversos conceitos de desenvolvimento, não somente econômico, mas relacionado também a coletividade, identificando-se aspectos territoriais, políticos, sociais, formatando-se assim os objetivos das pesquisas, que foram as avaliações das relações dos agricultores familiares frente as ações e características que promovam a geração ou acúmulo de Capital Social, seja em territórios específicos ou em programas governamentais a eles disponibilizados.

Na concepção de que o Capital Social tem como objeto principal o processo de interrelação entre indivíduos ou grupos, na Tabela 5 identificou-se as amostras utilizadas nas pesquisas, onde massivamente foram estudados os agricultores familiares e suas famílias, porém com relação a intervenções sociais do Estado representadas por políticas públicas, 
citando o PAA - Programa de Aquisição de Alimentos e PNRA - Programa Nacional de Reforma Agrária.

Em quantidades menos abrangentes, mas ainda assim importantes, constatou-se as inter-relações dentro da estrutura social, representado por levantamentos com membros de instituições de fomento ao desenvolvimento rural, conselhos municipais, organizações de produtores e unidades consumidoras, agentes do poder público, diretores de cooperativas e movimentos sociais, representantes de organizações federais e estaduais. As transformações e a modernização da agricultura, em particular da agricultura camponesa e familiar, estão ligadas, entre outros, a processos de ação coletiva e a diversas formas de organização dos agricultores (Abramovay, 1999; Sabourin, 1999, apud Sabourin, 2005, pg. 02).

Tabela 5 - Amostras utilizadas nos estudos para levantamento de Capital Social

\begin{tabular}{|l|c|c|}
\hline Amostras utilizadas nos estudos & Qtde & \% \\
\hline Famílias de agricultores familiares & 418 & $\mathbf{4 8 , 7 \%}$ \\
\hline Apicultores beneficiários e não beneficiários do PAA & 110 & $\mathbf{1 2 , 8 \%}$ \\
\hline Agricultores familiares assentados pelo programa nacional de reforma agrária & 92 & $\mathbf{1 0 , 7 \%}$ \\
\hline Agricultores familiares dirigentes de sindicatos ou associações & 56 & $\mathbf{6 , 5 \%}$ \\
\hline Agricultores beneficiários do PAA & 50 & $\mathbf{5 , 8 \%}$ \\
\hline Agricultores associados de Associações de pequenos produtores rurais & 27 & $\mathbf{3 , 1 \%}$ \\
\hline Agricultores familiares & 25 & $\mathbf{2 , 9 \%}$ \\
\hline Agricultores inseridos na cadeia produtiva do leite & 21 & $\mathbf{2 , 4 \%}$ \\
\hline Representantes de instituições de apoio e fomento ao desenvolvimento rural & 16 & $\mathbf{1 , 9 \%}$ \\
\hline Membros do CMDRS & 15 & $\mathbf{1 , 7 \%}$ \\
\hline Entidades consumidoras (PAA) socioassistenciais & 7 & $\mathbf{0 , 8 \%}$ \\
\hline Organizações produtoras (PAA) de agricultores & 7 & $\mathbf{0 , 8 \%}$ \\
\hline Agentes do poder público & 5 & $\mathbf{0 , 6 \%}$ \\
\hline Membro de conselhos de assistência social e segurança alimentar & 2 & $\mathbf{0 , 2 \%}$ \\
\hline Diretores de Cooperativas de Agricultura Familiar & 2 & $\mathbf{0 , 2 \%}$ \\
\hline Diretores de movimentos sociais de trabalhadores rurais & 2 & $\mathbf{0 , 2 \%}$ \\
\hline Representantes de organizações federais - CONAB & 2 & $\mathbf{0 , 2 \%}$ \\
\hline Diretor de Central de Cooperativas de Agricultura Familiar & 1 & $\mathbf{0 , 1 \%}$ \\
\hline Membro de organização estadual - SEAPA & 1 & $\mathbf{0 , 1 \%}$ \\
\hline TOTAL & $\mathbf{8 5 9}$ & $\mathbf{1 0 0 , 0 \%}$ \\
\hline & & \\
\hline
\end{tabular}

Fonte: Dados da pesquisa, 2019.

Na Tabela 6, encontra-se o levantamento sobre os autores mais citados em relação ao tema Capital Social. Primeiramente, pode-se verificar as respectivas áreas de formação dos autores, predominantemente sociologia, seguido por economia e ciência política. Identificouse nas pesquisas três autores clássicos que conceituam o tema, Robert David Putnam, Pierre Félix Bourdieu e James Samuel Coleman, os quais foram utilizados como referência em DOI: http://dx.doi.org/10.22295/grifos.v30i52.5254 | Edição Vol. 30, Núm. 52, 2021. 
várias teses e dissertações. São perspectivas e conceitos propostos pelos autores nos anos 80, anos 90 e 2000 e utilizadas até a atualidade.

Tabela 6 - Principais autores citados relacionado ao tema Capital Social

\begin{tabular}{|l|l|c|c|}
\hline Principais autores citados & Formação & Qtde & \% \\
\hline Robert David Putnam - 1993/1995/1996/2000/2002 & Cientista Político & 16 & $\mathbf{9 , 7 \%}$ \\
\hline Pierre Félix Bourdieu - 1979/1980/1983/1985/1986/1998/2001 & Sociólogo & 13 & $\mathbf{7 , 9 \%}$ \\
\hline James Samuel Coleman -1988/1990 & Sociólogo & 7 & $\mathbf{4 , 2 \%}$ \\
\hline Ricardo Abramovay - 1998/2000/2001/2003/2009 & Economista & 7 & $\mathbf{4 , 2 \%}$ \\
\hline Alejandro Portes - 1988/1996/1998/2000 & Sociólogo & 5 & $\mathbf{3 , 0 \%}$ \\
\hline Mark Granovetter - 1973/1984/1985 & Sociólogo & 4 & $\mathbf{2 , 4 \%}$ \\
\hline Nan Lin - 1999/2001 & Sociólogo & 3 & $\mathbf{1 , 8 \%}$ \\
\hline Michael Woolcock - 1998/1999/2000 & Economista & 3 & $\mathbf{1 , 8 \%}$ \\
\hline Citações relacionadas a 1 e 2 autores & & 107 & $\mathbf{6 4 , 8 \%}$ \\
\hline TOTAL & & $\mathbf{1 6 5}$ & $\mathbf{1 0 0 , 0 \%}$ \\
\hline
\end{tabular}

Fonte: Dados da pesquisa, 2019.

Cabe destaque também para Ricardo Abramovay, autor referenciado em vários dos objetos de estudo, podendo considerar dentre os citados, o mais contemporâneo. Mark Granovetter, dentro das distintas abordagens de capital social, traz a ideia de inserção, que vem originalmente de Karl Polanyi, mas foi introduzida na sociologia contemporânea por Granovetter (1985) (WOOLCOCK, 1998).

Alejandro Portes, outro autor citado, traz o conceito de Capital Social, em uma perspectiva mais utilitarista, em que os atores buscam obter benefícios pelo fato de pertencer a redes sociais ou a outras estruturas sociais, e traz os aspectos negativos e não apenas as virtudes, afirmando que se pode criar " « maus públicos » : fenômenos de exclusão daqueles que não fazem parte das redes; cobrança excessiva dos membros das redes, pressão social para a conformidade nos pequenos grupos ou solidariedade ligada a uma experiência de desconfiança perante o resto da sociedade "(SABOURIN, 2005, p.4).

Pode-se verificar na Figura 02, que a rede é densa quanto relacionada aos autores Putnam e Bourdieu, estando referenciados em várias das obras estudadas, seguidos por Abramovay, Coleman, Granovetter e Portes, assim, pela estrutura apresentada e posição dos autores, conclui-se que seus conceitos são relevantes sobre o tema, proporcionando avanços nas pesquisas sobre capital social. 


\section{Figura 02 - Rede de autores relacionados ao tema Capital Social}

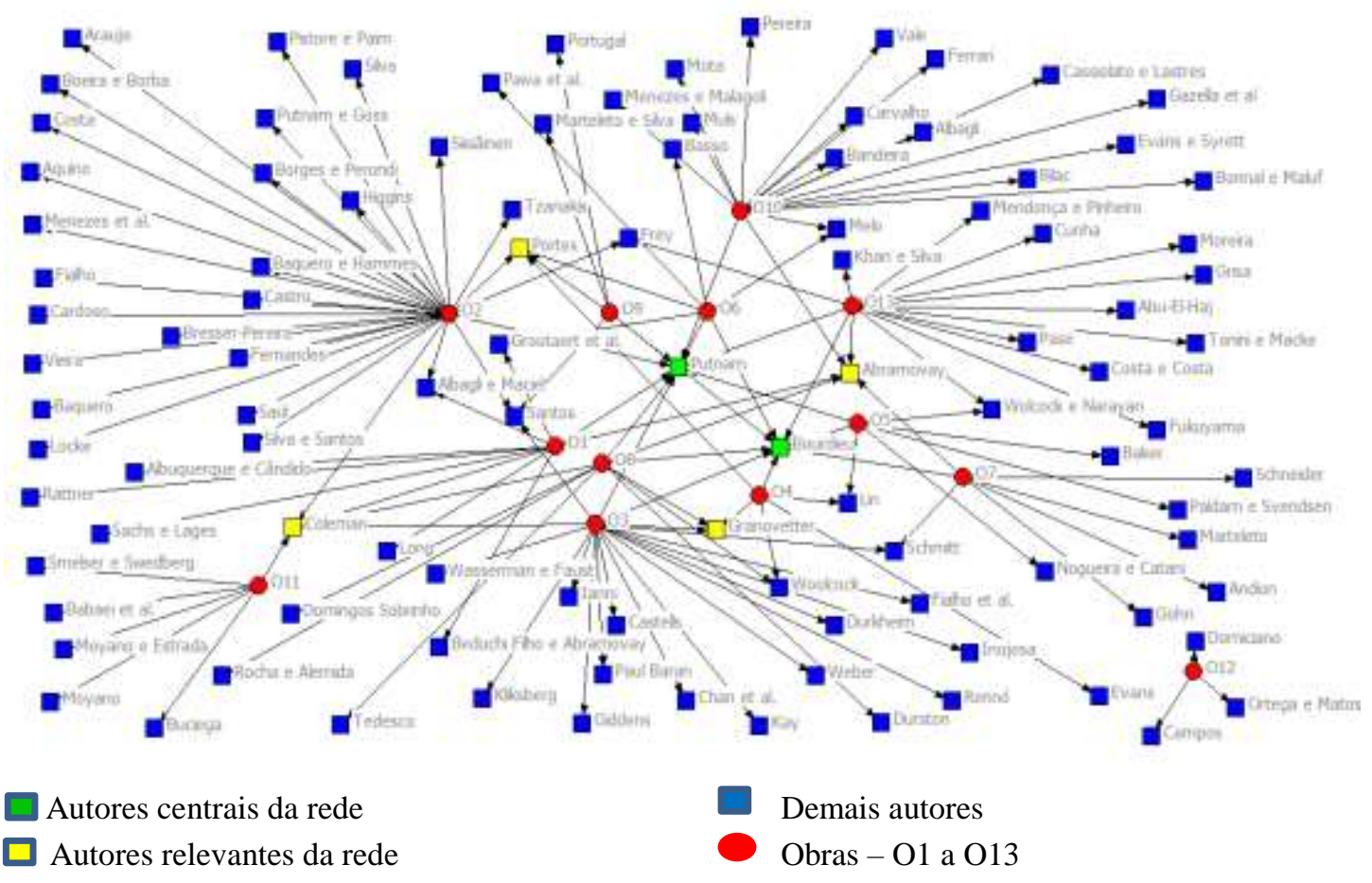

Fonte: Dados da pesquisa, 2019.

Rech, Clamer, Terribile e Macke (2017) analisaram a produção acadêmica sobre a relação entre capital social e desenvolvimento econômico e em seus resultados identificaram que os três autores mais citados são Putnam, Bourdieu e Coleman, corroborando com os achados dessa pesquisa. Os autores Silva, Silva e Silva (2009) também apontam em sua pesquisa a relevância de Bourdieu, Coleman e Putnam para o capital social.

O objeto do estudo, o eixo central da pesquisa, vinculado ao Capital Social, demonstrou conforme a Tabela 7, que as políticas públicas foram os temas mais tratados e o PAA dentre os principais assuntos das pesquisas, buscando identificar como estes atores se comportaram em relação a esta política pública, seus níveis de organização em relação as suas atividades agrícolas e mercantis para a conquista ou não desse mercado, dinamizado pela iniciativa do poder público.

Outro ponto identificado está relacionado a questão espacial, ou seja, os vários territórios que foram identificados nos estudos, Raffestin (1993) relata que os espaços e territórios apresentam princípios distintos, território é antecedido pelo espaço, sua formação 
vem da ação do homem, definindo-o através de relações de poder econômico, político e cultural, sendo elemento essencial para a análise da realidade.

Nas pesquisas com enfoque territorial, verificou-se as ações dos atores dentro desses espaços, identificando-se análises de agregação socioambiental, percepção de atores sobres desenvolvimento, pluriatividade, problemas socioeconômicos e formação de redes.

\section{Tabela 7 - Objetivos dos estudos e sua relação com o tema Capital Social}

\begin{tabular}{|l|c|c|}
\hline Capital Social em relação aos objetivos dos estudos & Qtde & $\%$ \\
\hline Capital Social associado a Política Públicas para a Agricultura & 7 & $\mathbf{5 3 , 8 \%}$ \\
\hline Capital Social associado à Agricultura & 3 & $\mathbf{2 3 , 1 \%}$ \\
\hline Capital Social associado a Redes Sociais & 2 & $\mathbf{1 5 , 4 \%}$ \\
\hline Capital Social associado a problemas socioeconômicos & 1 & $\mathbf{7 , 7 \%}$ \\
\hline TOTAL & $\mathbf{1 3}$ & $\mathbf{1 0 0 , 0 \%}$ \\
\hline Pontos específicos citados nos objetivos & $\mathbf{Q t d e}$ & $\mathbf{\%}$ \\
\hline PAA & 3 & $\mathbf{2 3 , 1 \%}$ \\
\hline PAA / PNAE & 1 & $\mathbf{7 , 7 \%}$ \\
\hline PAA / PNAE / PNPB & 1 & $\mathbf{7 , 7 \%}$ \\
\hline PRONAF & 1 & $\mathbf{7 , 7 \%}$ \\
\hline PRONAT / PROINF & 1 & $\mathbf{7 , 7 \%}$ \\
\hline Territórios: agregação socioambiental & 1 & $\mathbf{7 , 7 \%}$ \\
\hline Territórios: percepção de atores sociais envolvidos no DRS & 1 & $\mathbf{7 , 7 \%}$ \\
\hline Territórios: pluriatividade familiar & 1 & $\mathbf{7 , 7 \%}$ \\
\hline Territórios: problemas socioeconômicos & 1 & $\mathbf{7 , 7 \%}$ \\
\hline Territórios: redes sociais de trabalho & 1 & $\mathbf{7 , 7 \%}$ \\
\hline Territórios: redes solidárias & 1 & $\mathbf{7 , 7 \%}$ \\
\hline TOTAL & $\mathbf{1 3}$ & $\mathbf{1 0 0 , 0 \%}$ \\
\hline & & \\
\hline
\end{tabular}

Fonte: Dados da pesquisa, 2019.

No Quadro 3, elencou-se as sínteses das conclusões com os propósitos das teses e dissertações, compartilhando alguns elementos-chave. Inicialmente, em termos de objetivos relacionado a políticas públicas e Capital Social, com relação aos aspectos positivos dos resultados alcançados, pode-se concluir que a efetividade de uma política pública, aumenta os níveis de renda e Capital Social, contribui para a formação de redes e atos cooperativos, estabelecendo relações sócio institucionais, oportunizando e identificando oportunidades, impactando nas relações sociais dos agricultores.

Quadro 3 - Principais conclusões dos estudos e sua relação com o tema Capital Social Objetivo Política pública: PAA

\section{Síntese das conclusões}

A efetividade social do PAA foi influenciada pela tipologia de rede formada quanto a estrutura e ao foco de atuação que são heranças do Capital Social.

DOI: http://dx.doi.org/10.22295/grifos.v30i52.5254 | Edição Vol. 30, Núm. 52, 2021. 


\begin{tabular}{|c|c|}
\hline Política pública: PAA & $\begin{array}{l}\text { O estudo em profundidade da rede social do PAA mostrou suas fraquezas e sua frágil } \\
\text { sustentabilidade, configuradas no domínio da rede exercido por poucos atores que } \\
\text { monopolizam os fluxos de relações entre os demais componentes, podendo interpretar-se, } \\
\text { em termos de Capital Social, como um signo de debilidade. }\end{array}$ \\
\hline Política pública: PAA & $\begin{array}{l}\text { A questão idade, escolaridade, capacitações, ter apicultura como atividade principal reduz } \\
\text { a chance de os apicultores alcançarem melhores níveis tecnológicos. A quantidade de mão } \\
\text { de obra capacitada e o índice de Capital Social aumentam o nível tecnológico e os } \\
\text { impactos do PAA são positivos sobre a produtividade, renda e nível de Capital Social dos } \\
\text { apicultores. }\end{array}$ \\
\hline $\begin{array}{l}\text { Política pública: PAA / } \\
\text { PNAE }\end{array}$ & $\begin{array}{l}\text { Constituição das organizações de agricultores familiares realizada por agentes externos, } \\
\text { associada ao acesso a recursos e bens públicos, resultando baixa adesão em instâncias } \\
\text { participativas, não apresenta a composição ideal para a dinamização de Capital Social. }\end{array}$ \\
\hline $\begin{array}{l}\text { Política pública: PAA / } \\
\text { PNAE / PNDB }\end{array}$ & $\begin{array}{l}\text { Cooperativas contribuem no alcance de políticas públicas por parte dos ag } \\
\text { familiares, estabelecendo relações socio institucionais que seriam menos pra } \\
\text { acessíveis individualmente, sendo que concertações entre agricultores e suas c } \\
\text { podem constituir espaços de trabalho colaborativo. }\end{array}$ \\
\hline $\begin{array}{l}\text { Política } \\
\text { PRONAF }\end{array}$ & $\begin{array}{l}\text { O perfil empreendedor melhora a situação econômica e social na Agricultura Familiar, } \\
\text { oportunizando a identificação de oportunidades de trabalho, novos meios e técnicas de } \\
\text { produção, novos produtos e mercados. }\end{array}$ \\
\hline $\begin{array}{l}\text { Política pública: } \\
\text { PRONAT / PROINF }\end{array}$ & $\begin{array}{r}\text { Demonstram que o PROINF, ao proporcionar a } \\
\text { impactos nas relações sociais e empoderamento } \\
\text { municipais (CMDR) pela baixa densidade de } r \\
\text { conectados mesmo depois do PROINF, } 1\end{array}$ \\
\hline \begin{tabular}{l|l} 
agregação \\
ttal
\end{tabular} & $\begin{array}{l}\text { Nível médio de Capital Social, apontando fragilidade na formação de orga } \\
\text { políticas públicas voltadas ao desenvolvimento e assistência técnic }\end{array}$ \\
\hline $\begin{array}{l}\text { Territórios: } \\
\text { de percepção } \\
\text { envolvidos no DRS }\end{array}$ & $\begin{array}{l}\text { Identificou-se em relação as instituiçães de apoio e fomento ao desenvolvimento rural, } \\
\text { que na visão de seus representantes legais são importantes instrumentos de } \\
\text { desenvolvimento, já na visão dos agricultores familiares a atuação das mesmas está } \\
\text { aquém de suas demandas, necessitando uma maior participação dos atores na construção } \\
\text { de programas e políticas para o desenvolvimento rural. Identificados níveis médio baixo e } \\
\text { baixo relacionados a participação em grupos sociais, políticos e institucionais, indicando } \\
\text { dificuldade na formação de Capital Social e construção de redes. }\end{array}$ \\
\hline $\begin{array}{l}\text { os: } \\
\text { idade familiar }\end{array}$ & $\begin{array}{c}\text { A adoção de práticas pluriativas proporcionou a melhoria na qualidade de vida e que há } \\
\text { presença de Capital Social nessas famílias, porém sem planejamento formal e estratégico } \\
\text { para unificação das famílias em torno da atividade pluriativa e Capital Social para o } \\
\text { combate da pobreza rural. }\end{array}$ \\
\hline $\begin{array}{l}\text { s: problemas } \\
\text { ômicos }\end{array}$ & $\begin{array}{l}\text { O trabalho em conjunto é impedido pela ausência de Capital Social, sendo que entraves } \\
\text { sociais, econômicos e infraestruturas dificultam a sua formação. }\end{array}$ \\
\hline $\begin{array}{l}\text { Territórios: redes } \\
\text { sociais de trabalho }\end{array}$ & $\begin{array}{l}\text { Identificou-se um contexto de trabalho precário que pode gerar sofrimento físico e mental, } \\
\text { o que é compensado com redes informais de trabalho que envolvem amizade, confiança, } \\
\text { reciprocidade e cooperação (Capital Social), contribuindo para uma produção que não } \\
\text { seria possível apenas com a força de trabalho da família. }\end{array}$ \\
\hline $\begin{array}{l}\text { Territórios: } \\
\text { solidárias }\end{array}$ & $\begin{array}{c}\text { Evidencia-se níveis elevados de Capital Cultural entre os Agricultores Familiares que tem } \\
\text { contribuído para o fortalecimento dos territórios analisados; contudo, como obstáculo ao } \\
\text { fortalecimento do Capital Social está a imposição do Estado na obrigatoriedade de } \\
\text { organização formal entre os agricultores. }\end{array}$ \\
\hline
\end{tabular}

Fonte: Elaborado pelos autores, adaptado de BDTD, 2019.

Identificou-se nos estudos aspectos de como o desenvolvimento do capital social (relações de confiança, reciprocidade) dos agricultores atua para o desenvolvimento rural, buscando a valorização dos recursos naturais, incremento de renda e inclusão social nas áreas rurais. Em relação as políticas públicas e programas, apresentam alternativas para a construção dessas políticas no sentido de promover o desenvolvimento rural nas dimensões 
econômica, social e ambiental. Quanto as dificuldades, existe uma similaridade nos estudos quando relacionados aos níveis não satisfatórios de Capital Social, identificando como fatores geradores a fragilidade de formação de organizações e políticas públicas, baixa participação em grupos sociais, políticos e institucionais, falta de planejamento formal e estratégico, entraves socioeconômicos e estruturais e imposição do estado em relação a organização formal entre os agricultores.

\section{CONSIDERAÇÕES FINAIS}

O presente estudo teve como objetivo analisar a produção científica relacionadas ao portfólio de dissertações de mestrado e teses de doutorado sobre Capital Social no contexto da Agricultura Familiar, defendidas entre os anos de 2014 a 2019, pela importância de se criar Capital Social para o desenvolvimento rural.

A análise bibliométrica de forma geral, permite identificar, além das contribuições dos estudos, as lacunas de pesquisa. A grande maioria dos trabalhos tratou das políticas públicas para os agricultores familiares e observou-se que se faz importante a execução de projetos e estudos que avaliem e busquem maior articulação e diálogos entre os programas e os atores/instituições, considerando as especificidades do público (agricultores familiares) e do ambiente de implantação (meio rural). Avaliar também se a política pública - PAA merece aprimoramento em suas formulações, para atender de forma mais adequada a realidade dos agricultores familiares. Identificou-se estudos nas regiões Centro Oeste, Nordeste e Sudeste, mas nenhum estudo na Região Sul, que é uma região importante na agricultura, já que detém 74,3\% de participação de área territorial no Brasil, conforme o último Censo Agro 2017 (IBGE, 2020).

Pode-se afirmar que a pesquisa teve como limitação o período do recorte metodológico, além de não ter se baseado em artigos acadêmicos que são um dos subprodutos dos programas de pós-graduação Stricto Sensu, buscando ampliar a amostra. Mas, é importante acrescentar que a análise teve como amostra um universo representativo, com procedimentos metodológicos bem definidos e as análises feitas a partir das fontes secundárias disponíveis na Biblioteca Digital de Teses e Dissertações. 
Propõe-se para futuros estudos envolvendo a temática Capital Social e Agricultura Familiar para o desenvolvimento local a partir de experiências na região Sul do Brasil, identificando a influência de características específicas para a formação de Capital Social.

\section{REFERÊNCIAS}

ABRAMOVAY, R. Uma nova extensão rural para a Agricultura Familiar. In: Seminário Nacional de Assistência Técnica e Extensão Rural, 1., 1997, Brasília. Anais. Brasília: PNUD, 1997.

O Capital Social dos territórios: repensando o desenvolvimento rural. Economia aplicada, v. 4, n. 2, p. 379-397, 2000.

ALBAGLI, S.; MACIEL, M. L. Capital Social e empreendedorismo local. Proposição de, 2002.

ALBAGLI, S.; MACIEL, M.L. Capital social e empreendedorismo local. Projeto de Pesquisa Políticas para Promoção de Sistemas Produtivos Locais de MPME Brasileiras. Rio de Janeiro: UFRJ/IE - RedeSist - FINEP - SEBRAE, 2002. Disponível em http://www.ie.ufrj.br/rede. Acesso em 15 out 2019.

ARAÚJO, C. A. Bibliometria: evolução histórica e questões atuais. Em Questão, Porto Alegre, v. 12, n. 1, p. 11-32, jan./jun. 2006. Disponível em:< http://revistas.univerciencia.org/index.php/revistaemquestao/article/viewFile/3707/3495>.

Acesso em: 04 set 2019.

AZEVEDO, J. F. Capital cultural e território: os nós, os laços e a trama das redes de agricultores familiares do município de Nossa Senhora da Glória - SE. 2015. 256 f. Tese (Pós-Graduação em Geografia) - Universidade Federal de Sergipe, São Cristóvão, 2016.

BOURDIEU, P. Le Capital Social: notes provisoires. Actes de la recherche en sciences sociales, v. 31, n. 1, p. 2-3, 1980.

The Forms of Capital. Originalmente publicado em "Ökonomisches Kapital, kulturelles Kapital, soziales Kapital” in Soziale Ungleichheiten (Soziale Welt, Sonderheft 2). (pp. 248-257) Tradução de Richard Nice. Disponível online em <http://www.pontomidia.com.br/raquel/resources/03.html>. Acesso em 04 set 2019.

O capital social - notas provisórias'. In: Nogueira, M. A. e A. Catani (orgs.) Pierre Bourdieu: escritos de educação. Capítulo III. Petrópolis, RJ: Vozes, 1998.

BARBOSA, S. K. G. Capital Social e as associações de Agricultura Familiar em Paudalho, Pernambuco. 2014. 101 f. Dissertação (Programa de Pós-Graduação em Administração e Desenvolvimento Rural) - Universidade Federal Rural de Pernambuco, Recife, 2014.

DOI: http://dx.doi.org/10.22295/grifos.v30i52.5254 | Edição Vol. 30, Núm. 52, 2021. 
BARBOSA, Nilson Araujo, M. Sc., O Capital Social como fator de desenvolvimento rural sustentável nos serviços de ATER do INCAPER. 2016. 191 f. Dissertação (Programa de Pós-Graduação em Extensão Rural). Universidade Federal de Viçosa - MG, 2016.

CAMARGO, R. S. O efeito do programa territorial nas relações sociais dos agricultores familiares do território da cidadania do vale do Rio Vermelho - Go. 2014. 87 f. Dissertação (Mestrado em Agronegócio) - Universidade Federal de Goiás, Goiânia, 2014.

CAMPANHOLA, C. GRAZIANO DA SILVA, J. O agroturismo como nova fonte de renda para o pequeno agricultor brasileiro. In: ALMEIDA, J. RIEL, M. (org.) Turismo Rural: ecologia, lazer e desenvolvimento. Bauru: EDUSC, 2000.

CASTRO, I. Problemática qualitativa e quantitativa do capital social: uma exploração. In SOCIUS Working Papers. $\mathrm{N}^{\mathrm{o}}$ 3, janeiro, 2006. P. 1-33. Disponível em: http://www.repository.utl.pt/bitstrream/10400.5/1974/1/wp.200603.pd. Acesso em: 19 mai 2020.

CERVO, A.L.; BERVIAN, P.A. Metodologia científica. 3. ed. São Paulo: McGraw-Hill do Brasil, 1983

COLEMAN, J. S. Social capital in the creation of human capital. American journal of sociology, v. 94, p. S95-S120, 1988.

ELESBÃO, I. O espaço rural brasileiro em transformação. Finisterra, XLII, 84, 2007, pp. 47-65

FAVARETO, A.S. Paradigmas do Desenvolvimento Rural em Questão - do agrário ao territorial (Tese de Doutorado). Programa de Pós-Graduação em Ciência Ambiental da Universidade Federal de São Paulo. São Paulo, 2006.

FLORES, A.F.; MARINI, M.J. Capital social e governança local no contexto dos arranjos produtivos locais: um estudo bibliométrico. IGepec, Toledo, v. 22, n.1, p. 83-99, jan./jun. 2018.

IBGE - INSTITUTO BRASILEIRO DE GEOGRAFIA E ESTATÍSTICA. Disponível em: https://censos.ibge.gov.br/agro/2017/templates/censo_agro/resultadosagro/index.html. Acesso em 25 mai 2020.

LONG, N.; PLOEG, J. D. Van der. Heterogeneidade, ator e estrutura: para a reconstituição do conceito de estrutura. In: SCHNEIDER, S.; GAZOLLA, M. Os atores do desenvolvimento rural: perspectivas teóricas e práticas sociais. Porto Alegre: UFRGS, 2011. p. 23-48. 
LUCAS, E.O. ZORITA, J.C.G. Produção Científica sobre Capital Social: estudo por acoplamento bibliográfico. Revista da Faculdade de Biblioteconomia e Comunicação da UFRGS v. 20, n.3 - Edição Especial 2014.

MACHADO, J. A. Redes sociais e acesso a políticas públicas de compra governamental da Agricultura Familiar: um estudo de caso do município de Guaraciaba- MG. 2016. 88 f. Dissertação (Mestrado em Extensão Rural) - Universidade Federal de Viçosa, Viçosa. 2016.

MAZZUCHETTI, R.N. STOFELL, J. TARIFA, M.R. Capital social e desenvolvimento rural: Estudo empírico em cooperativas de agricultura familiar no Estado do Paraná. Revista de Gestão e Organizações Cooperativas - RGC RGC - Santa Maria, RS, v.4, n.8, jul./dez 2017

MARTINS, J. W. L. Redes sociais de trabalho do agricultor familiar e Maranguape, Ceará. 2017. 102 f. Dissertação (Programa de Pós-Graduação em Psicologia) - Universidade de Fortaleza, Fortaleza, 2017.

MILANI, C. R. S. Nem cola, nem lubrificante sociológico, mas campo eletromagnético: as metáforas do Capital Social no campo do desenvolvimento local. Redes, Santa Cruz do Sul, v.12, n.1, p.195-224, jan/abr 2007.

MEDEIROS, L. G. Pronaf, empreendedorismo rural e Capital Social: uma análise das famílias assentadas no município de Rio Verde - GO. 2019. 132 f. Dissertação (Mestrado em Agronegócio) - Universidade Federal de Goiás, Goiânia, 2019.

OLIVEIRA, B. E. R. Desenvolvimento rural sustentável e as condições de vida dos agricultores familiares na Zona da Mata mineira: os casos comparados de Tombos e Araponga. 2014. 179 f. Tese (Doutorado em Ciências Ambientais) - Universidade Federal de Goiás, Goiânia, 2014.

PUTNAM, R. D. Comunidade e democracia: a experiência da Itália moderna. Editora FGV, 2000.

Bowling Alone. The collapse and Revival of American Community. New York: Simon e Schuster, 2000.

RAFFESTIN, C. Por uma Geografia do Poder. São Paulo: Ática, 1993.

RAMBO, A.G. et al. Território e Desenvolvimento na Escala Humana: condições de vida e gestão territorial no Sul do Rio Grande do Sul. $50^{\circ}$ Congresso da Sober, Vitória - ES, 2012. Disponível em: < http://www.ufrgs.br/pgdr/arquivos/841.pdf > Acesso em 05 set 2019. 
RECH, M.; CLAMER, R.; TERRIBILE, S.R.I.; MACKE, J. Capital social e desenvolvimento econômico: um estudo bibliométrico. REVISTA BRASILEIRA DE DESENVOLVIMENTO REGIONAL, BLUMENAU, 5 (2), P. 181-199, 2017

ROCHA, G. S. Capital Social, pluriatividade e desenvolvimento local: tratos e retratos no sudoeste da Bahia. 2016. 325 f. Tese (Pós-Graduação em Geografia) - Universidade Federal de Sergipe, São Cristóvão, SE, 2016.

ROCHA, J. H. Agricultura Familiar e Mercados Institucionais (protegidos): estudo sobre o Programa de Aquisição de Alimentos (CPR Doação) em Boa Vista, Roraima. 2015. 341f. Tese (Doutorado em Agronomia) - Programa de Pós-Graduação em Sistemas de Produção Agrícola Familiar, Faculdade de Agronomia Eliseu Maciel, Universidade Federal de Pelotas, Pelotas, 2015.

SABOURIN, E. Organização dos agricultores e produção de valores humanos. SOCIEDADE BRASILEIRA DE SOCIOLOGIA XII CONGRESSO BRASILEIRO DE SOCIOLOGIA 31 de Maio a 3 de junho de 2005, FAFICH/UFMG Belo Horizonte, Minas Gerais, Brasil, 2005.

SANTOS, L. L. Capital Social e redes: uma análise do programa de aquisição de alimentos da Agricultura Familiar. 2014. 151 f. Tese (Doutorado em Sociologia) Universidade Federal de Goiás, Goiânia, 2014.

SANTOS, M.J.; VIEIRA, E.T.; SANTOS, D.F. Desenvolvimento social e econômico: crescimento populacional e capital social no município de Caraguatatuba/SP. Qualitas Revista Eletrônica ISSN 16774280 v.19, n.1, jan/abril 2019, p. 75-94

SCHNEIDER, S. Teoria social, Agricultura Familiar e pluriatividade. Revista brasileira de ciências sociais. São Paulo. Vol. 18, n. 51 (fev. 2003), p. 99-122, 2003.

SOBREIRA, D. B. Avaliação dos impactos do programa de aquisição de alimentos (PAA) no estado do Ceará: $O$ caso do mel. 2014. 162 f.: Dissertação (mestrado) Universidade Federal do Ceará. Mestrado Acadêmico em Economia Rural (MAER). Centro de Ciências Agrárias. Fortaleza - CE. 2014.

SOUSA, G. M. R. Capital Social e desenvolvimento da Agricultura Familiar no Ceará. 2015. 92 f.: Dissertação (mestrado) - Universidade Federal do Ceará, Departamento de PósGraduação em Economia Rural, Fortaleza - CE, 2015.

SOUZA, R. G. Alcance de políticas públicas federais no cooperativismo da Agricultura Familiar em Goiás do ano de 2007 ao ano de 2014: fragilidades e potencialidades. 2016. 160 f. Dissertação (Mestrado em Agronegócio) - Universidade Federal de Goiás, Goiânia, 2016. 
VANTI, N. Da bibliometria à webometria: uma exploração conceitual dos mecanismos utilizados para medir o registro da Informação e a difusão do conhecimento. Ciência da Informação, v. 31, n. 2, p. 152-162, 2002.

WANDERLEY, M. de N.B. A valorização da Agricultura Familiar e a reivindicação da ruralidade no Brasil. Desenvolvimento e Meio Ambiente, v. 2, 2000.

WOOLCOCK (1998). "Social Capital and Economic development: Toward a Theoretical Synthesis and Policy Framework". Theory and Society 27: 151-208, 1998. 